\title{
Haiti: Interim Poverty Reduction Strategy Paper-Joint Staff Advisory Note
}

The attached Joint Staff Advisory Note (JSAN) on the Interim Poverty Reduction Strategy Paper for Haiti, prepared jointly by the staffs of the World Bank and the IMF, was distributed with the member country's Poverty Reduction Strategy Paper (PRSP) to the Executive Boards of the two institutions. The objective of the JSAN is to provide focused, frank, and constructive feedback to the country on progress in implementing its Poverty Reduction Strategy (PRS).

To assist the IMF in evaluating the publication policy, reader comments are invited and may be sent by e-mail to publicationpolicy@imf.org.

Copies of this report are available to the public from

International Monetary Fund $\bullet$ Publication Services

$70019^{\text {th }}$ Street, N.W. • Washington, D.C. 20431

Telephone: (202) 623-7430 • Telefax: (202) 623-7201

E-mail: publications@imf.org •Internet: http://www.imf.org

\section{International Monetary Fund Washington, D.C.}





\author{
THE INTERNATIONAL MONETARY FUND \\ AND \\ THE INTERNATIONAL DEVELOPMENT ASSOCIATION
}

\author{
REPUBLIC OF HAITI \\ Joint Staff Advisory Note (JSAN) \\ of the Interim Poverty Reduction Strategy Paper (I-PRSP) \\ Prepared by the Staffs of the International Monetary Fund (IMF) \\ and the International Development Association (IDA) \\ and \\ Approved by Ranjit Teja and Mark Plant (IMF) \\ and Pamela Cox (IDA)
}

November 6, 2006

\title{
I. INTRODUCTION
}

1. This document represents the joint advice of the staffs of the World Bank and the International Monetary Fund on the Interim Poverty Reduction Strategy Paper (I-PRSP) prepared by the Government of Haiti and submitted to IDA and the IMF on September 29, 2006. This I-PRSP outlines the main areas of actions envisaged by the authorities to reduce poverty as well as the steps to be undertaken in the preparation of the full Poverty Reduction Strategy (PRS). The full PRSP would be expected to build on the I-PRSP by presenting a comprehensive medium- and long-term strategy and an agenda for its implementation; prioritizing public expenditures and strengthening its policy focus, including the link between policy and resource use; elaborating a clear framework for the coordination and monitoring of the strategy; and defining actions to enhance public sector program and project implementation capacity. For this purpose the PRSP would need to identify operational plans and monitorable targets, the cost of programs, and the links with the budget.

\section{BACKGROUND}

2. From mid-2004 to mid-2006, Haiti's economic and social recovery and its structural reforms were supported by partners from the international community under an Interim Cooperation Framework (ICF), which a Transition Government presented at a July 2004 
Donor Conference in Washington. Within the framework of the ICF, the Government succeeded in creating the conditions for holding free and fair elections so as to bring the transition period to a successful end, strengthening economic governance institutions and practices, and reversing the protracted economic decline, while less progress was made in improving access of the population to basic services, notably electricity and water. The ICF was also meant to serve as a bridge to a Poverty Reduction Strategy, whose preparation was expected to be undertaken by a democratically elected government in a participatory way.

3. Following the successful presidential and parliamentary elections held in early 2006, the Government presented an extended and revised one-year ICF at a Donor Conference held in Port-au-Prince on July 25, 2006. The objective of this extended framework was to secure donor support for its economic and social development agenda over the period July 2006September 2007, while a participatory medium-term poverty reduction strategy would be prepared. The I-PRSP reflects the Government's development agenda presented at the conference and details the process it will follow for the preparation of the full PRSP over the coming year.

\section{THE INTERIM PRSP}

4. A draft I-PRSP was initially prepared in late 2005 by the Transition Government and subsequently revised by the current Government to reflect its development priorities. To reduce poverty and promote growth the I-PRSP emphasizes the importance of achieving private sector led growth, enhancing physical infrastructure, expanding access to social services, and providing support for the productive sectors (agriculture, industry and tourism), while at the same time improving economic governance and strengthening public institutions. Staffs consider the Government's emphasis on these areas to be appropriate, particularly in light of the deficiencies of past policies and programs. The I-PRSP also (i) makes reasonably good use of the existing poverty data; (ii) highlights the role of budgetary discipline and economic governance for development outcomes; and (iii) describes the process for preparing the full PRS.

\section{A. Poverty Analysis}

5. The I-PRSP presents a good diagnostic of the current dimensions of poverty in Haiti. The poverty analysis is based on a wide range of available information, including a living conditions survey (2001), a poverty perceptions survey (2003), poverty maps (2000, 2002, and 2004), a household budget and consumption survey (2000) and a population census (2003). Over 50 percent of the population live below the US\$1 a day poverty line and 76 percent below US\$2 a day poverty line. Poverty is largely a rural phenomenon, as incidence of poverty in rural areas is 69 percent for the US\$1 a day poverty line and 86 percent for the US\$2 a day poverty line. Although the available information provides a 
rich quantitative and qualitative basis for assessing poverty in Haiti, including the dimensions of geography, age, education and gender, more recent data are needed in order to have a good baseline for measuring progress towards the Millennium Development Goals (MDGs). Data collection for an updated demographic and health survey, which includes questions on household expenditure, will be completed in 2006. A new household budget and consumption survey is also being conducted and the results are expected to be available in 2007. The staffs recommend that these ongoing surveys be completed in a timely manner and their results be used to target future policy actions in the PRSP and as a base for measuring progress toward achieving the MDGs.

\section{B. Macroeconomic Framework}

6. The I-PRSP covers well the authorities' macroeconomic objectives and the broad measures necessary to reach these objectives. Staffs recommend that the PRSP provide more information on the appropriate sequencing and timing of key structural reform measures consistent with the objectives in the Government's three-year macroeconomic program supported by the Poverty Reduction and Growth Facility (PRGF) arrangement with the IMF.

7. The Government's three-year macroeconomic program provides the framework to support strengthening of institutional capacity and increased provision of key social services. Staffs suggest that the PRSP highlight that the key objectives of the macroeconomic program are to a) raise growth to over 4-5 percent over the medium term; b) reduce inflation, which levies a disproportionate tax on the poor and impedes sustainable growth; c) increase revenues to sustain higher social and infrastructure expenditures and reduce reliance on external financing; $d$ ) improve public expenditure management to increase the governance and transparency of public expenditures; and e) strengthen the financial sector, including microfinance institutions, to maintain macroeconomic stability and promote private sector investment.

8. Staffs also suggest that the PRSP define an appropriate institutional framework for local governments. In the absence of a well-defined institutional framework clarifying the relationship between the central and local governments and the sources and modalities for financing of their operations, the establishment of local governments could lead to fiscal instability.

9. Staffs recommend that the PRSP emphasize the importance of maintaining debt sustainability after debt relief and improving external debt management. External financing needs will need to be met in the form of grants or highly concessional loans, to ensure that debt levels remain sustainable after debt relief. In addition, the PRSP will need to identify areas for improvement of debt management, such as through centralization of debt information, better coordination between government entities and strengthening the legal framework. 


\section{Structural Reforms}

10. A number of existing sectoral studies and strategies could be useful in developing Haiti's structural reform agenda. The linkages between specific development problems, poverty reduction objectives and structural reforms envisaged under the Government's program could have been better articulated in the I-PRSP. While structural reforms are presented as overall goals, including in the policy matrix, the staffs recommend that the PRSP indicate how the authorities intend to make these reforms operational and monitorable, and that these be discussed with stakeholders as part of sectoral action programs. This, for instance, applies to the Government's plans to implement the Education For All program and expand the school feeding program in the education sector and its stated priority of addressing the issues of political instability and violence (including through measures to reform the judiciary and the police), which are identified in the I-PRSP as major binding constraints to growth in Haiti. Also, the Government's Program d'Apaisement Social (PAS), which correctly emphasizes the importance of addressing urgent social and economic needs in disadvantaged and conflict-prone areas, should be incorporated in the PRSP.

11. The I-PRSP emphasizes that improved economic governance and public sector modernization constitute important objectives to improve the investment climate and public resource use in Haiti. The I-PRSP describes the recent reforms implemented by the authorities in these areas and their broad objectives going forward. Also, the policy matrix identifies several reforms planned by the Government over the coming year to improve public financial management, strengthen fiscal management and enhance revenue mobilization. These include, among others, actions to ensure accountability and oversight of government and public enterprise accounts, expand the computerized financial management system to all public institutions, strengthen procurement procedures, and establish customs control in the provinces. The PRSP could also emphasize the importance of implementing procedural and legal reforms to increase the tax base.

12. Service delivery mechanisms and the contribution of partner NGOs and the private sector could be further developed in the PRSP. The staffs recommend that the PRSP consider mechanisms to make service delivery more transparent and effective by providing information to and engaging users in the planning, delivery and evaluation of services. In addition, in light of existing public sector institutional and financial constraints, the Government intends to draw on the (profit and non-profit) private sector for basic service provision, particularly in the health and education sectors. In this respect, it is recommended that the respective roles and complementarities of local government, partner NGOs and the private sector be clearly defined in the relevant sector strategies presented in the full PRSP. An example of recent Government's ongoing efforts in this area that the PRSP could highlight is the establishment of a new National Partnership Office which will act as a coordinator of public and private actors in the education sector. 
13. Given existing implementation capacity, it will be important that the PRSP focus on selected actions in the identified priority areas and that related investment projects be prioritized in the public investment program, particularly in the areas related to social sectors and rehabilitation of the physical infrastructure. Staffs also recommend that the PRSP outline future efforts to strengthen institutional capacity in the key public sector agencies that are essential for the implementation of priority actions defined by the Government and for underpinning private sector led growth. The PRSP could also include a more comprehensive list of technical assistance requirements, including identification of donors who could provide assistance in the specific priority areas.

14. Local Government capacity will also need to be strengthened. The I-PRSP highlights the significant differences in poverty indicators and service provision between Port-au-Prince and the rest of the country. Welfare indicators and access to public services are particularly worrisome in rural areas. Staffs welcome the Government's regional focus and recommend that implementation capacity of local public agencies be carefully assessed and measures to strengthen it be clearly identified in the PRSP.

\section{Participation, Coordination And Monitoring}

15. Broad and meaningful public consultations can build ownership and sustainability around reforms and priorities outlined in the PRSP. The main objectives of the Government's development program for the period July 2006 to September 2007 were communicated at the July 25, 2006 conference which was attended by broad sections of stakeholders and donors (including parliamentarians, the private sector, civil society and the media) and whose proceedings were fully broadcast through the radio and television to the Haitian population. The I-PRSP summarizes the consultative process that the Government intends to implement for the preparation of the full PRSP together with a program and calendar for national and local consultations. Staffs welcome this program of consultation and commend the Government for its focus on a representative, well structured and decentralized process. Staffs encourage the Government to build on lessons learned from other countries which have undertaken similar participatory processes. Staffs also encourage the authorities to seek technical and financial assistance from donors to support the participatory process and strengthen the government statistical and monitoring capacity. The objectives of these processes should be clearly defined and focus on listening to a wide range of voices and identifying priorities within a constrained budget environment.

16. The PRSP can be an important vehicle to enhance donor coordination. In particular, it could provide a framework to ensure that donor assistance for the implementation of critical priorities (notably security) is aligned with and well integrated into the country's strategy. The Government has consulted with donors on the main objectives of its development program for the coming year and the I-PRSP highlights the importance of ensuring cohesion 
and coordination of donors actions. The staffs recommend the continuation of regular consultations with the donor community with a view toward increasing the level of donor coordination in program design and implementation.

17. Procedures to monitor and evaluate progress in implementing the poverty reduction strategy would have to be devised. The I-PRSP contains a comprehensive matrix of strategic measures. The full PRSP should define follow-up monitoring and evaluation mechanisms, including identifying a number of a few key objectively verifiable indicators that are at the heart of the strategic goals of the PRSP and the institutional framework for monitoring the PRSP implementation. The mechanisms should also include elements of participation by civil society. Staffs recommend that the authorities seek to mobilize technical assistance from donors and other sources to improve the statistical capacity in key areas related to the monitoring efforts.

\section{Preparation of The PRSP}

18. Costing of programs and projects will be important for the PRSP. Priority should be given to costing proposed programs and projects, assessing policy effectiveness, and prioritizing them in light of existing financial resources (domestic and external) and absorption capacity. This should help to ensure that the PRS is realistic and aligned to the budget cycle.

19. The PRSP needs to be results-oriented and establish well-publicized benchmarks. The objective is to make the PRSP an effective vehicle for coordinating and reporting on progress made in the implementation of the Government's medium-term development agenda. This requires: (i) establishing efficient mechanisms and easy to monitor indicators for progress, including for the MDGs; (ii) refining the structural reform agenda and providing more detailed and focused sector strategies; (iii) clearly defining priority expenditures in the framework of a strengthened public sector investment program; and (iv) enhancing public sector program and project implementation capacity.

\section{RISKS AND CHALLENGES}

20. Haiti's economy is subject to large risks, particularly from political instability, recurring insecurity and natural disasters. The country is also vulnerable to shocks from high energy costs and the loss of donor support, since the largest part of the public investment program is financed by external grants. As in many fragile states, Haiti is faced with many pressing priorities and, on the one hand, high expectations among citizens and, on the other, capacity constraints. Thus, the need to balance expectations with the capacity to deliver on the implementation and monitoring of the PRSP is also a challenge. Staffs recommend that 
the full PRSP recognize these risks and outline Government's ongoing and planned actions to mitigate them.

\section{ISSUES FOR DISCUSSION}

21. Do Directors agree with staffs' conclusions regarding: (i) priority areas for strengthening the poverty reduction strategy to be formulated in the PRSP; and (ii) areas in which further analysis or adjustments to the strategy are needed for the PRSP to provide a framework for future Bank and Fund assistance. 